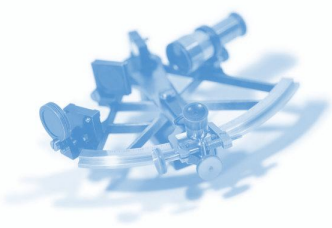

\section{Paul Chin}

Physical Sciences Centre

Department of Chemistry

University of Hull

Hull HU6 7RX

p.a.chin@hull.ac.uk

\section{Perhaps without realising} it, we all use technology that will have an impact on the way students are able to learn.

\section{Using assistive technology in the classroom}

\begin{abstract}
The use of technology is now ubiquitous in Higher Education but its use or application to promote student inclusivity is not always well recognised. The use of existing software or hardware with a little more thought can often bring serendipitous benefits for a range of students. The JISC funded service, TechDis (www.techdis.ac.uk) offer periodic funding under its HEAT (Higher Education Assistive Technologies) scheme to promote the use of technology for inclusive teaching. TechDis says that 'The aim of this scheme is to provide staff working in HE... with technology ... with which to develop or uncover an aspect of good inclusive practice. This may be specific to the teaching of a particular discipline, supporting a specific role area, or may have more generic applicability across the sector'. This article will discuss how TechDis funding was used with students to assess its potential benefits for inclusive teaching.

\section{Introduction}

Perhaps without realising it, we all use technology that will have an impact on the way students are able to learn. Although recent disability legislation aims to reduce risks to students with recognised disabilities, some of our practices are not always so obviously inclusive. For example, some dyslexic students may have difficulty reading black text on a white background, so making copies available on different coloured paper can help. In the lecture theatre we often use presentations but how visible are they to students and if we try to engage students by asking them questions, how many break out into a cold sweat? As an example of using assistive technology (or perhaps more accurately, using technology in a more assistive way) the author reports on the use of technology for more inclusive teaching. The technology used was a Gyration wireless mouse and compact keyboard to support student interaction during a scheduled class.
\end{abstract}

\section{TechDis project bid}

The TechDis project was aimed at using the Gyration wireless technology as an example of how technology can support student interaction and feedback to encourage a more inclusive participation in the lecture theatre. It was intended that this would be a good example of how assistive technology can be used to encourage greater participation of students during lectures, especially from students who are too scared to interact in such public situations or who may have difficulty due to other reasons, perhaps through disability.

\section{Overview of equipment}

The Gyration wireless gyroscopic optical mouse and compact keyboard is produced by the company of the same name. It has an 'innovative mouse with gyroscopic motionsensing technology for in air navigation' and 'up to 30 '/9m range thanks to $2.4 \mathrm{GHz} \mathrm{RF}$ (radio frequency) technology (Fig. 1).

The product website lists the following features of the product:

Ergonomic mouse design for comfortable desktop and in-air use

Compact cordless keyboard with whisper quiet keys for maximum productivity and minimum clutter

- Gyroscopic motion-sensing technology for in-air use provides navigation with no delay while the precise optical sensor is perfect for desktop use

Three distinct programmable mouse buttons

$2.4 \mathrm{GHz}$ RF receiver with up to $30^{\prime} / 9 \mathrm{~m}$ range with no line-of-sight limitations

$\mathrm{NiMH}$ rechargeable battery with desktop charging cradle

GyroTools ${ }^{\mathrm{TM}}$ Media Control software for Microsoft Windows ${ }^{\circledR}$ ( ${ }^{*}$ Software installation required). 


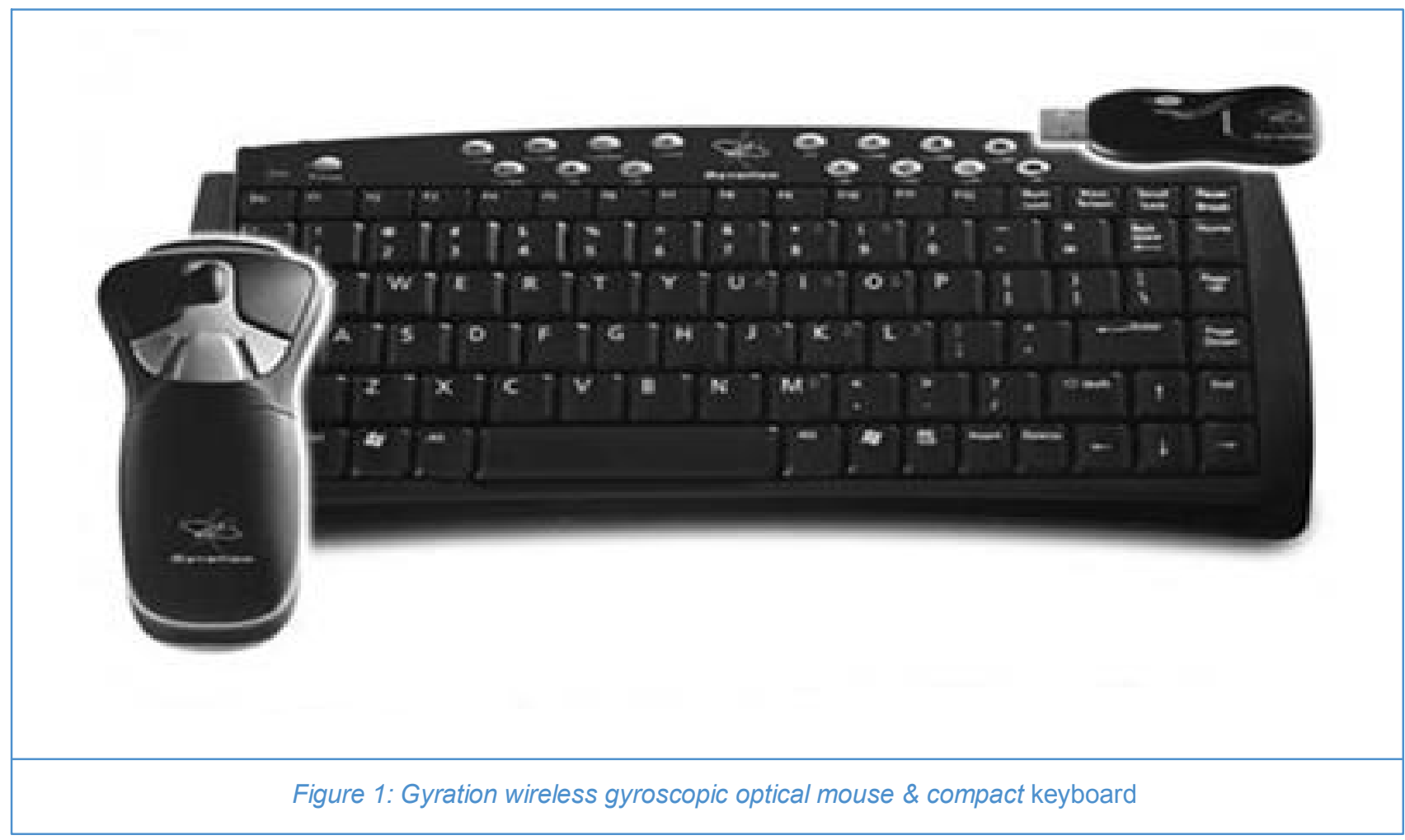

\section{Intended outcomes of project}

The first aim of the project was to trial the Gyration keyboard and mouse and to assess whether the equipment functioned appropriately according to the product claims. The second aim was to evaluate whether the integration of the equipment into a teaching environment might enhance the learning process by encouraging greater student participation. The third major aim was to attempt to evaluate the potential of the equipment for use as assistive technology. This could involve the support of students who may be shy and have difficulty interacting during class or have difficulty interacting for other reasons such as physical disabilities. Therefore, the three major outcomes of this project were:

1. Assess the functionality of the Gyration equipment

2. Trial the use of the Gyration equipment in an active teaching environment

3. Assess the potential of the equipment as assistive technology.

\section{Overview of teaching activity}

The Gyration wireless equipment has the potential for students to participate in a class or lecture room setting in a more interactive manner. An old tried and tested method for engaging students in the 'classroom' is to ask them to come up to the (chalk/white) board and ask them to write answers or responses for the rest of the class to view. There is, however, a double edged outcome to this.

Involving students gives them the opportunity to address fellow classmates and experience giving a 'presentation' which is a valuable interpersonal skill. A downside however, is that some students find this prospect daunting and in a large room of students there may be limited time to engage more than a handful of students for logistical reasons (time to come to the front of the class etc). Given these constraints the intention for the teaching activity was for the tutor to move around the room passing the equipment to different students during the session so that they could offer interactive feedback and input to the activities.

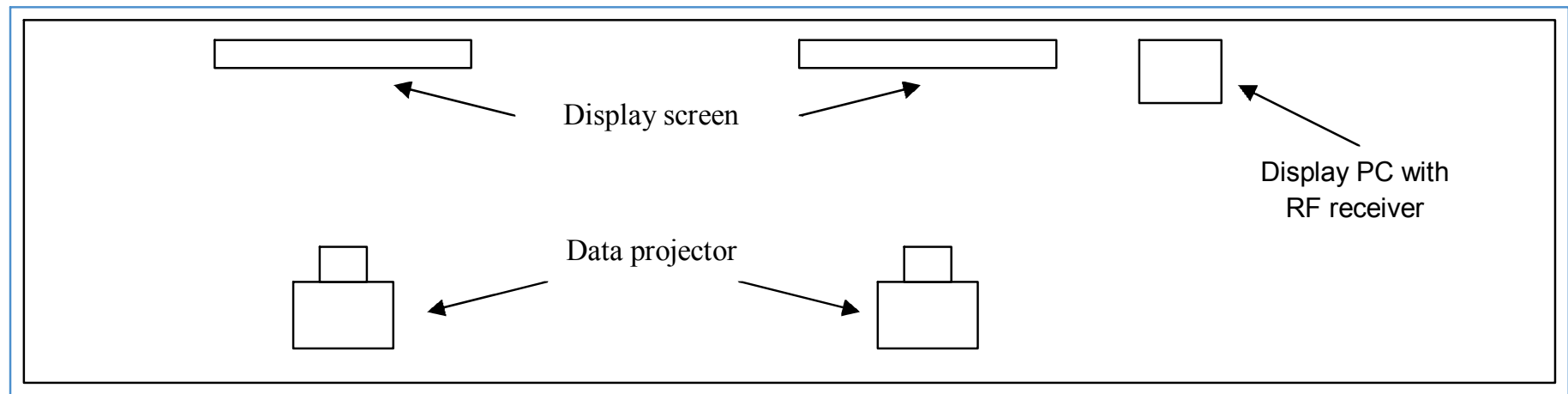

Figure 2: Schematic layout of room (approximate set up and not to scale) 
The equipment was trialled during two IT classes for first year students, each with about seventy students. The tutor was able to move around the class during the demonstration parts of the session, taking questions and providing more timely and targeted feedback using the wireless equipment. This was in contrast to the usual static style where the tutor is usually stuck at the front having to demonstrate everything on the display PC connected to the data projector. This potentially allowed for more interactive demonstrations and questioning from students who might otherwise have been afraid to ask a question in front of the whole group. With the tutor moving around the class students may be more inclined to ask questions since they were near the tutor instead of having to shout the question out to the whole class. In addition to the demonstrations the students were given an extensive exercise to undertake during class where the intention was for them to demonstrate their work as the activity progressed.

\section{Observations from study \\ The Gyration wireless keyboard and mouse was used in an IT teaching room that is rectangular in shape and approximately 30 metres in length. It has one display PC and two data projectors, as shown in Fig 2.}

\section{During a typical class given in a more formal presentation style from the front, only a few students would normally ask questions. In this trial, far more students asked questions when presented with the equipment.}

Use of the equipment also enabled far more interactive demonstrations in response to direct queries. In a be confident enough to ask a question whereas in this trial the author received over 20 questions from the students. The students were able to use the equipment to elucidate their query and these students provided further feedback by completing a brief anonymous survey at the end of the class. The results of the survey are discussed below. complete and were allowed

\section{Equipment functionality}

Given the fact that the RF (radio frequency) receiver was a USB device connected to the display PC, meant that the signal did not reach the far left of the room for the equipment to operate all the time. The manufacturer suggests the product has a range of about 9 metres so its potential is limited by the size of the room. The equipment may work better in a standard (tiered) lecture theatre but the opportunity to pass the equipment around may be more restricted given the usual seating arrangements in a lecture theatre; ie it is not possible to move in and around rows of seats. However, given the stated specifications of the equipment, the Gyration product worked well.

\section{More students asking questions}

Whilst this was only one trial with two classes, this course has been taught by the author for several years. This means that it is possible to make the qualitative observation that by using the equipment and moving amongst the students, rather than presenting from the front, students seemed far more comfortable asking questions than usual. During a typical class given in a more formal presentation style from the front, only a few students would normally ask questions. In this trial, far more students asked questions when presented with the equipment.

\section{Potential for assistive technology}

One interesting observation made during the trial was the difficulty some students had using the display screen with the equipment. Students were given a task to to work in groups of two or three. When they were asked to use the equipment they had to use the display $\mathrm{PC}$ connected to the data projector. This meant that the students had to look at the projector screen to view their work. The author soon realised that some students who wore glasses had difficulty seeing the screen in order to work on the computer. This could restrict the potential for such use for any student with visual impairments, even those with relatively 'minor' impairments who use

glasses to correct their vision.
However, there was a positive response with this approach to student interaction. During the student exercise students were working in groups with no input from the rest of the class. This meant that when the author asked individual students from various groups to demonstrate parts of the exercise activities on the screen, there was less pressure since the whole class was not specifically looking. This meant that students felt more relaxed about getting involved and were more willing to attempt the activities than if they had to do it in front of the whole class. This use of the equipment clearly has potential for shy students to get involved in a class to help build their confidence.

\section{Student survey findings}

From the two classes in the trial, about 25 students had the opportunity to use the Gyration equipment. These students were asked to offer feedback on their use of the equipment by completing an anonymous survey at the end of the class. The author received 19 replies, which can be considered representative of the study. The students were asked if they found the technology easy to use and whether the equipment made the session more interactive. In each case $95 \%$ of respondents said that the equipment was easy to use and the session became more interactive. The short survey also asked if they would like to use the equipment again and $100 \%$ of respondents replied 'yes'. 
As a potential for supporting disabled students as assistive technology, the students were asked if they felt the equipment may offer benefits for disabled students and $84 \%$ replied 'yes'. A number of responses were given claiming that the technology would help students who were struggling with the topic during class and so would help their learning. The following are some quotes recorded:

"Using interactive technology really helps students to understand parts of the course that they don't, and helps the lecturer to pick up on students who are too shy to say they cannot complete a task. Interaction can also make the lectures more interesting and allows students to become used to new technology they would normally not be able to experience."

"...to help pupils who are particularly struggling with a subject as it will allow help to be shown on a larger scale to help other pupils if they are also struggling."

"The wireless technology allows the lecturer to be more interactive with the students."

\section{Discussion}

Given the fact that this was a short trial with only two classes, a number of interesting issues were raised. Referring back to the three planned outcomes of the project, the first related to the functionality of the equipment. The signal strength of the $\mathrm{RF}$ receiver limits the potential for use in large rooms. The author also found that whilst the 'in air' functionality of the mouse was useful, it took a bit of practice to get used to. This involved dexterity skills to use the mouse accurately. When the students tried to use the equipment for the first time they found the mouse difficult to use in the air and so had to use it as a traditional mouse on the desk. The author feels that this may limit its use as assistive technology for students who have mobility issues. However, in terms of enabling a teaching session to become more interactive, it clearly works.

For the second aim to trial the equipment's use in an active teaching environment, the results were very positive. The author was able to engage far more students than would normally be possible in a 'traditional' class. Students found the use of the equipment less threatening and so were more willing to engage and ask questions.

As potential for the Gyration product to provide good assistive technology in the class, the current trial did not manage to cover fully its potential. Students with mild visual impairments (wearing glasses) had difficulty using the equipment because they could not see the screen properly. However, this is not necessarily the fault of the equipment but more to do with the general set up of visual aids in the room. Students with other disabilities such as physical tremors may find the gyro mouse difficult to use but overall the author felt the equipment was a success when used to engage more students who might otherwise be too shy to interact in class.

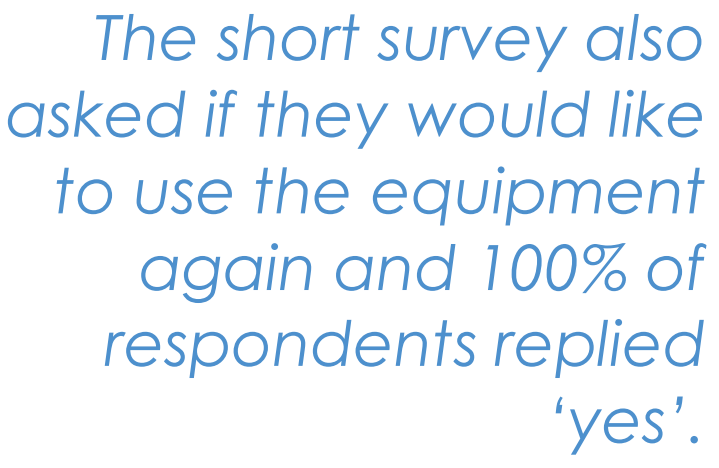

